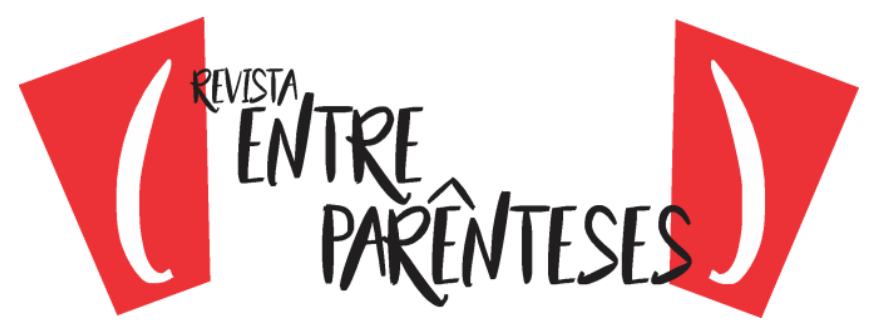

\title{
O NARRADOR DE O TRIBUNAL DA QUINTA-FEIRA E SEU CRIME
}

\author{
Lisiane Andriolli Danieli ${ }^{1}$ \\ Universidade Federal do Rio Grande \\ Coordenação de Aperfeiçoamento de Pessoal de Nível Superior \\ (lisiad@gmail.com)
}

\begin{abstract}
RESUMO: Este trabalho objetiva analisar o último livro de Michel Laub, $O$ tribunal da quinta-feira (2016), quanto aos conteúdos abordados - internet, homossexualidade, HIV/Aids - e as propriedades formais da obra - narrador em primeira pessoa, formas tecnológicas. A ficção de Laub aborda temas diversos e pode ser investigada por vários vieses. Propõe-se este estudo apoiado em conceituações sobre narrativa em primeira pessoa de Maria Lúcia Dal Farra (1978) e Käte Hamburger (1976). Além disso, a pesquisa de aspectos da literatura contemporânea será abordada a partir de teóricas como Regina Dalcastagnè (2001) e Heloísa Buarque de Hollanda (s/d), argumentando-se que o fator narrativo é pertinente à leitura da obra, tornando quem lê empático ao enredo e ao personagem principal. Ainda que o narrador em primeira pessoa aparentemente retire a vilanidade de suas atitudes, a violência simbólica e verbal de um discurso divulgado na internet passa a ser pensada de modo a não se ignorar o alvo de tal violência nem seu praticante.
\end{abstract}

Palavras-chave: Michel Laub; narrador; internet.

ABSTRACT: This paper aims to analyze the last book by Michel Laub, O Tribunal de quinta-feira (2016), regarding the contents addressed - internet, homosexuality, HIV / Aids - and the formal properties of the work - narrator in first person, technological forms. Laub's fiction addresses diverse subjects and can be investigated for various biases. This study is based on conceptualizations on firstperson narrative by Maria Lúcia Dal Farra (1978) and Käte Hamburger (1976). In addition, the research of aspects of contemporary literature will be approached from the theoretical ones like Regina Dalcastagnè (2001) and Heloísa Buarque de Hollanda (s / d), arguing that the narrative factor is pertinent to the reading of the work, making who reads empathic to the plot and the main character. Although the first-person narrator apparently removes the villainy from his attitudes, the symbolic and verbal violence of a discourse circulated on the Internet is now thought of so as not to ignore the target of such violence or its practitioner.

Keywords: Michel Laub; narrator; internet.

RESUMEN: Este trabajo tiene como objetivo analizar el último libro de Michel Laub, $O$ tribunal da quinta-feira (2016), en lo que se refiere a los contenidos abordados - internet, homosexualidad, $\mathrm{VIH} / \mathrm{SIDA}$ - y las propiedades formales de la obra - narrador en primera persona, formas tecnológicas. La ficción de Laub aborda temas diversos y puede ser investigada por varios sesgos. Se propone este estudio apoyado en conceptualizaciones sobre narrativa en primera persona de María Lúcia Dal Farra (1978) y Käte Hamburger (1976). Además, la investigación de aspectos de la literatura contemporánea se abordará a partir de teóricas como Regina Dalcastagnè (2001) y Heloísa Buarque de Hollanda (s/d), argumentando que el factor narrativo es pertinente a la lectura de la obra, haciendo el lector amistoso con el personaje principal. Aunque el narrador en primera persona aparentemente quita la villanía de sus actitudes, la violencia simbólica y verbal de un discurso divulgado en Internet pasa a ser pensada de modo que no se ignora el objetivo de tal violencia ni su practicante.

Palabras-clave: Michel Laub; narrador; internet.

${ }^{1}$ Mestranda em História da Literatura, bolsista pela CAPES, lisiad@gmail.com 


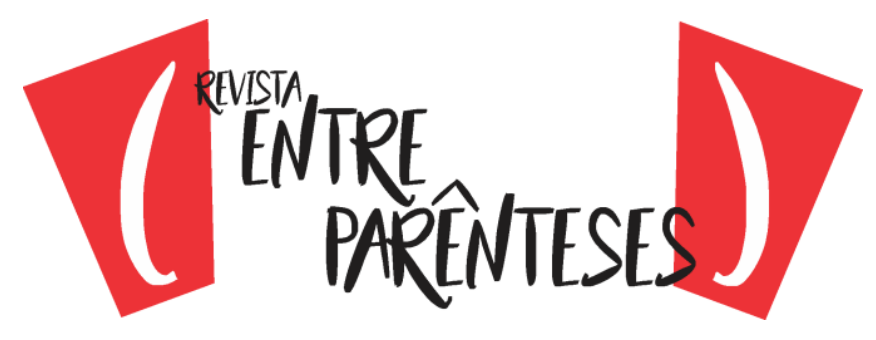

\section{Introdução}

Michel Laub é um escritor porto-alegrense radicado em São Paulo. Publica pela Companhia das Letras e seus últimos três livros, Diário da Queda (2011) A maçã envenenada (2013) e O tribunal da quinta-feira (2016), aqui analisado, fazem parte de uma trilogia, a qual trata, numa interpretação superficial, sobre violência e cotidiano, permeada de nomes de personalidades nacionais e internacionais.

Da mesma geração de escritores como Daniel Galera e Bernardo Carvalho, Laub fomenta uma escrita atravessada por traços que lembram sua vida. Não se pretendendo ater a biografismos, esta análise não considerará isso, ainda que existam características em comum entre narrador e autor, como a idade e a atuação profissional.

Pensando acerca de aspectos da literatura contemporânea abarcados por teóricas como Regina Dalcastagnè e Heloísa Buarque de Hollanda, o narrador em primeira pessoa tratado por Maria Lúcia Dal Farra e os limites entre público e privado no mundo tecnológico, este texto refletirá sobre $O$ tribunal da quinta-feira quanto aos conteúdos abordados, em especial o crime cometido pelo narrador, e as propriedades formais da obra.

\section{0 réu}

O narrador, por ser portador de voz, seleciona os acontecimentos a serem expostos no romance. Nesse sentido, a narrativa em primeira pessoa, conforme Maria Lúcia Dal Farra caracteriza, passa por uma manipulação em sua recepção na leitura. A visão está restrita ao ponto de vista determinado de quem narra, possibilitando o questionamento sobre a verdade ou não do que é narrado. Ademais, quem lê processa os fatos a partir de suas experiências pessoais, que modifica a interpretações ao que é exposto. 


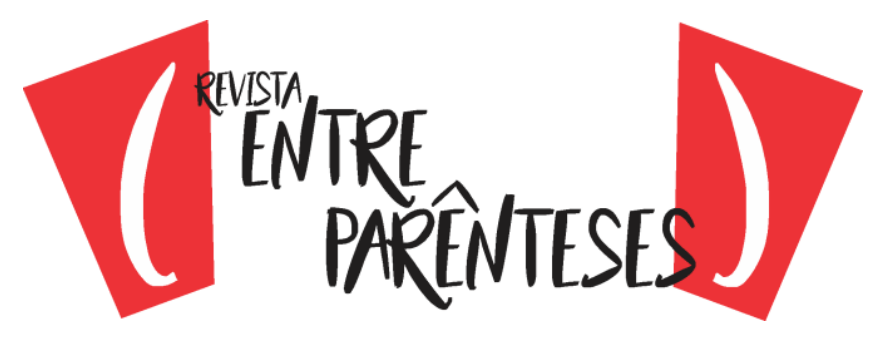

No livro estudado, o narrador é protagonista, conferindo-se a ele o papel de primeira pessoa protagonista (DAL FARRA, 1978, p. 27). A ele não é dada a capacidade de onisciência e a quem lê não se dá a capacidade de perceber os fatos além do contado, isto é:

Se [...] o narrador é representado- como no romance em primeira pessoa - a visão que o leitor terá dele será fundamentalmente diferente da que tem dos outros personagens, pois este será o sujeito da enunciação que é ao mesmo tempo sujeito do enunciado. (DAL FARRA, 1978, p. 36, grifos da autora)

O romance é uma tomada de partido, e seu ponto de vista e foco narrativo atestam isso. Portanto, José Victor, narrador da obra, passa-nos a sua imagem e a de outras personagens por sua perspectiva, limitando as informações que quem lê tem do todo. Nesse sentido, ao se narrar vivências pessoais, questiona-se a veracidade do descrito. Dessa forma, José Victor demonstra sua versão e sua defesa, as quais quem lê apenas acata: "As pessoas mentem para parecerem bem resolvidas, incorporam personagens para parecerem mais interessantes do que são, e que novidade pode haver nisso? Eu já pedi desculpas por ter feito um pouco de tudo isso com Dani no começo [...]" (LAUB, 2016, p. 114).

Como Käte Hamburger (1975, p. 228) expõe, "a interpretação do romance em primeira pessoa deve levar em consideração a relação do mundo humano narrado com o narrador-eu". Uma vez narrada em primeira pessoa, a obra mistura opiniões subjetivas do narrador e o fato narrado, não ocorrendo mais descrições fiéis da realidade. Sendo resultado da memória e ficcionalização, o texto agrega interferências do tempo e das sensações, isto é, José Victor narra não o fato, mas a impressão que tem dele.

Regina Dalcastagnè, como estudiosa da literatura brasileira contemporânea, atesta características de narradores e protagonistas desse momento. Os personagens entendem de frustrações e, em geral, são narradores. Dotados de poder ao narrar, passam a serem suspeitos e, assim, quem lê deve estar compromissado, devendo igualmente tomar partido do discurso: "Esses narradores confusos, indecisos ou obstinados, quando não abertamente mentirosos, 


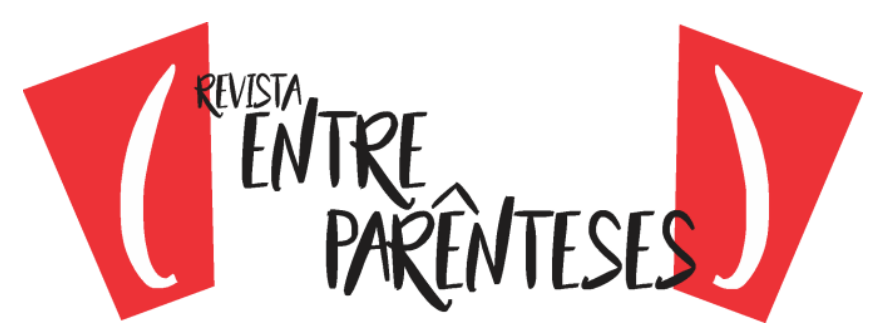

estão aí nos convidando a tomar partido e, assim que o fazemos, nos exibem quem somos." (DALCASTAGNĖ, 2001, p. 115). O tribunal da quinta-feira instiga o posicionamento em relação ao enredo, se quem lê será, com José Victor, réu ou, com Teca (e Dani), acusador.

Numa perspectiva que não é nova, o discurso privilegiado na obra é o hegemônico: homem, branco, heterossexual, adulto, urbano, em situação econômica favorável. Neste caso, o narrador é José Victor, um publicitário de 43 anos. As experiências que conta envolvem seu amigo, Walter, de mesma idade e profissão que ele. Para introduzir quem lê em sua narrativa, José Victor interpela: "É muito deselegante começar falando disso?" (LAUB, 2016, p. 7), ao iniciar sua narrativa citando a piada que o amigo Walter faz sobre merda. Como justificativa para tal, tem-se o fato de que, conforme o narrador, ter um corpo de 43 não impede de pensar como uma pessoa de 15 anos - é pertinente manter isso em mente no decorrer da narrativa, caso quem leia questione as atitudes do narrador.

\section{O tribunal}

A obra está dividida em quatro partes, cada uma simbólica em termos temáticos. A primeira, "A sigla", é uma alusão ao HIV e à Aids; a segunda, "A piada", representa o cerne do problema do livro; a terceira, "Os réus", expõe as vítimas e os culpados da "piada", mote da obra; a quarta e última parte, "Quinta-feira", refere-se ao passado e presente do narrador, seu julgamento nas redes sociais e as interpretações de Dani sobre o ocorrido.

Nas primeiras páginas do romance, entende-se que HIV e Aids serão tópicos abordados, assim como suas formas de contaminação e prevenção e personalidades importantes nacionais e internacionais que a tiveram e/ou morreram em decorrência da doença. $O$ amigo do narrador, já citado Walter, é o personagem homossexual que tem HIV, o que poderia reforçar estereótipos, ou dar visibilidade a um tema importante e marginalizado. Não é dada voz a tal personagem, uma vez que Walter só aparece por meio das mensagens que escreve e por citações do 


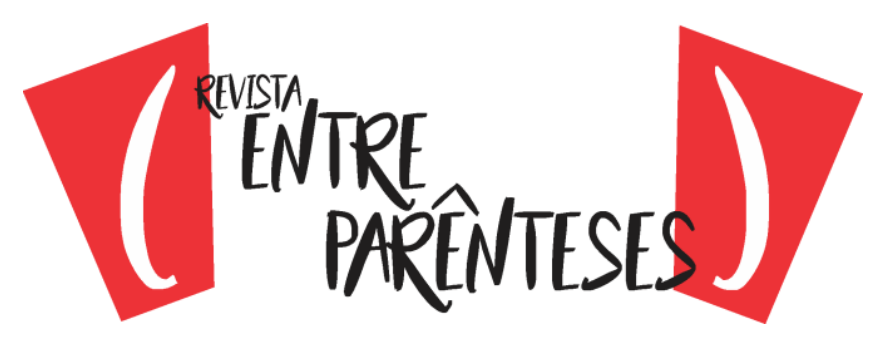

narrador. Cabe ao leitor interpretar essa representatividade sem fala do personagem como positiva ou negativa. Evidente que esta é uma característica da narrativa em primeira pessoa, que permite a quem lê ter apenas uma versão de todos os ocorridos.

José Victor trata do sexo de forma natural e legítima, listando suas parceiras sexuais, sua primeira relação e os aspectos que envolvem sua sexualidade e atividade sexual. São mencionados os slogans de campanha pró-uso de preservativo, como "quem ama protege" (LAUB, 2016, p. 17; 19), de 1990 ou 2000, e como isso não é uma lembrança possível no momento da transa, por isso a falta de preservativo por diversas vezes. As introduções à vida de José Victor foram feitas para que as/os leitoras sintam-se inteiradas das experiências do narrador e, por que não, cúmplices dele, compartilhando das mesmas vivências.

O narrador é separado de Tereza (Teca) há três meses no momento da narrativa. Será ela a responsável por tudo que acontece ao narrador porque ela quem descobre e divulga conversas privadas de e-mails trocados entre José Victor e Walter, as quais são o centro da narrativa, de alguma forma, pois causam o julgamento (nas redes sociais) sobre o narrador. É relevante citar que Heloísa Buarque de Hollanda ( $\mathrm{s} / \mathrm{d}$ ) expõe que as tecnologias, em especial a internet, fazem parte das produções textuais atuais e isso é inevitável, uma vez que estamos em um mundo com essas possibilidades narrativas. $O$ livro de Laub representa esse uso ao inserir mensagens de e-mail e comentários em redes sociais de forma cotidiana na narrativa.

De forma irônica, José Victor expõe estarmos em um tribunal diariamente: "Você pode escapar de uma época, mas não de todas as épocas. Bem-vindo ao tribunal. A audiência pode tomar seus assentos neste dia bonito de 2016." (LAUB, 2016, p. 24). Demarca-se, assim, o tempo. Estamos na atualidade (ano de lançamento do livro, inclusive) e nossas posições ideológicas são, portanto, de nossa época, que envolve a internet e os limites fluidos sobre o que é público e o que é privado. O uso de "tribunal" como forma de expressar o que está ocorrendo em relação ao que Teca divulgou é corrente para o narrador. É sua maneira de 


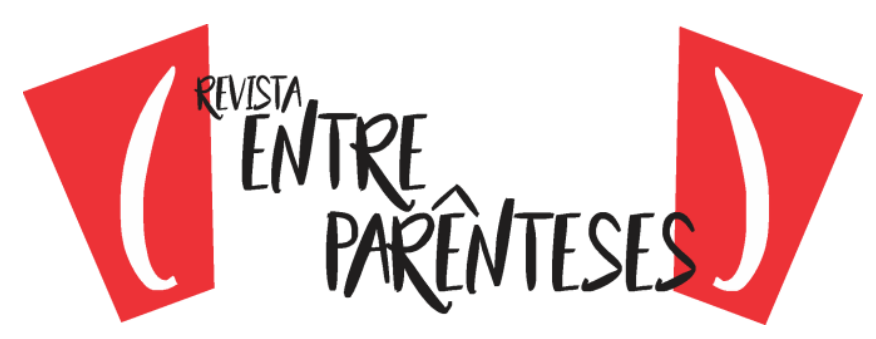

causar empatia ao público leitor, de modo que entendamos a situação e a gravidade forjada a ela.

Silêncio no tribunal, a sessão vai começar. [...] Bastam algumas piadas sobre merda. Basta meia dúzia de mensagens sobre cu. Basta uma dúzia de termos ofensivos registrados no presente eterno das caixas virtuais, e algo escrito há anos e em outro contexto equivale a uma ofensa cara a cara dita hoje. (LAUB, 2016, p. 29)

É indispensável tratar do objeto divulgado como descontextualizado, de anos antes do tempo narrado (2009), ainda que ofensivo a parcelas da população, como pessoas com HIV/Aids e mulheres (que também serão foco de alguns escritos). Além disso, o narrador aponta o fato de o mundo seguir enquanto a vida dele é afetada pelos acontecimentos, isto é, ele passa por um momento de julgamento on-line que não o impede de viver na concretude da realidade.

Na segunda parte do livro, José Victor considera falas que teria em 2010, se soubesse da divulgação de suas conversas em 2016, inclusive: "você tem até 2016 para avaliar minha real participação nessa história - para decidir se preciso responder por ela em público mais do que já estou respondendo em privado" (LAUB, 2016, p. 44). Os limites entre público e privado nos nossos tempos de internet são muito tênues, e o que é tratado no privado pode não ser entendido - e às vezes nem deve - por quem está de fora, o público. A esse respeito, Buarque de Hollanda (s/d) aponta o fato de que cultura da internet invariavelmente passará a fazer parte de nossas produções textuais, mudando a relação de quem lê com quem escreve:

Como se isso não bastasse, a relação autor/leitor é igualmente caótica e incontrolável, na medida em que, na rede, o leitor é levado a operar de forma múltipla em seu, digamos, encontro com um texto. Não me refiro aqui às infinitas possibilidades abertas pela leitura tão bem descritas pela teoria da recepção. Falo dos efeitos de uma leitura no interior de um ambiente não linear, totalmente descentralizado e, portanto bastante distinto da superfície fisicamente concreta e controlável de uma página de papel. (HOLLANDA, s/d) 


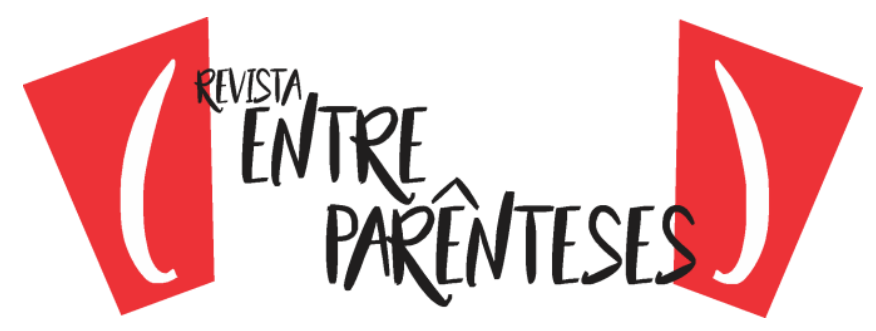

A forma como as conversas privadas são divulgadas é explicada pelo narrador. Teca, sua ex-mulher, tinha a senha de seu e-mail, acessa as mensagens e faz uma bricolagem delas - conforme sua vontade e podendo manipulá-las livremente -, encaminhando o arquivo para diversas amigas, que vão repassando e tudo passa a estar exposto nas redes sociais e na internet como um todo: "e eis que me vejo lá, no presente eterno do espaço virtual, para escrutínio e comentários de arquitetos, publicitários, economistas, professores, marceneiros, cobradores de ônibus e juízes interessados." (LAUB, 2016, p. 55). Apresenta-se, em certa medida, a vitimização do narrador, que está para ser julgado a partir da divulgação de mensagens pessoais.

Além das mensagens trocadas com Walter sobre suas atividades sexuais e sua condição de soropositivo, evidencia-se a traição ao casamento que o narrador cometeu com uma mulher: Dani, 23 anos mais nova que ele, redatora-júnior (portanto em cargo hierárquico inferior a ele) na mesma empresa em que trabalha. Nessa situação, enfatiza-se o fator da relação desigual em termos de poder que a idade e a posição social dos indivíduos agravam.

Pouco antes da terceira parte da obra, o narrador expõe que se seu crime fosse ter se apaixonado, traído a esposa e omitido sobre isso, ele aceitaria sua pena de bom grado; tendo em vista que seu crime é outro, indefinido, o qual vai além de conceituações acerca do que é público ou privado, ou fidelidade e compromisso propostos no matrimônio e desejo e indiferença em relação às outras pessoas; o tema da narrativa é a morte. Nesta terceira parte, o narrador reflete sobre o que poderia ter feito de diferente para que não passasse por tanto julgamento e críticas negativas em relação a si e suas mensagens, em especial sobre HIV e Aids, explicitando a contaminação de Walter. Além disso, ocorrem explicações sobre as mensagens ofensivas, que numericamente não são tão significativas, mas o tribunal as demonstra como se fossem, já que o recorte feito por Teca agrava a situação. Nesse sentido, tanto José Victor quanto Tereza são parciais e defendem seus pontos de vista, e quem lê conhece apenas as justificativas apenas do narrador, 


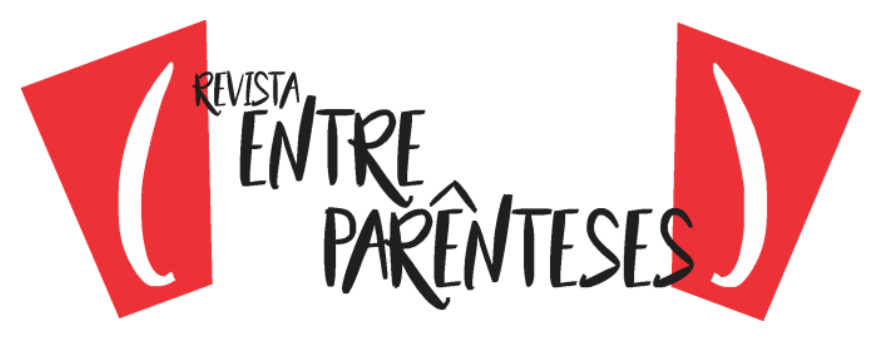

possibilitando, assim, a empatia com ele e seu crime, que passa a ser vislumbrado por sua perspectiva.

Uma das mensagens retratadas sobre Aids é ofensiva às pessoas com a síndrome e às mulheres: "Remetente: eu. Destinatário: Walter. Data: 3/1/2016. Trecho da mensagem: Teca está viajando. Estou pensando em convidar a vítima redatora-júnior para contrair A.I.D.S./S.I.D.A." (LAUB, 2016, p. 94). Leva-se em consideração o teor privado das mensagens e o quão difícil é compreender o contexto da amizade que possibilita tais "piadas". Contudo, não é praticável ignorar o potencial ofensivo delas e considerá-las como apenas brincadeira entre amigos. Determinados textos causam mal a grupos, e isso não deve ser simplesmente relevado.

Neste ponto, as mensagens tornam-se ofensivas às mulheres, representadas pela figura de Dani: "Remetente: eu. Destinatário: Walter. Data: 10/2/2016. Trecho da mensagem: Acho que para me apaixonar de vez e ser correspondido só falta disciplinar a redatora-júnior." (LAUB, 2016, p. 124, grifo meu). Seguida de: "Remetente: eu. Destinatário: Walter. Data: 10/2/2016. Trecho da mensagem: Uma disciplina adequada começa com uma boa surra de cinto." (LAUB, 2016, p. 125, grifo meu). O uso de do termo "disciplinar" e "disciplina" pode ter diversos sentidos, os quais me parecem todos negativos nesse contexto; a palavra pode passar a ideia de adestramento ou violência que seriam cometidas contra Dani (redatora-júnior). Assim, a "piada" incentiva violência; ainda que em uma mensagem privada, ela demonstra o pensamento público de José Victor.

Como finalização de tais mensagens que representariam ofensas não só à Dani, mas a toda uma classe, José Victor se justifica:

Agora além de um arrombado que incentiva outro arrombado a contaminar inocentes, e de um chefe que usa seu cargo para seduzir a redatora prostituta, e de um homem que perpetua a injustiça de gênero em nossa sociedade patriarcal, por causa da mensagem de 10/2/2016 virei também o equivalente a um agressor enquadrado na Lei Maria da Penha. [...] A violência consensual evocada por você como simbolismo erótico num e-mail, sinto informar, será transformada em violência unilateral praticada no mundo concreto. A piada virará fato, o personagem virará pessoa de carne e osso e 


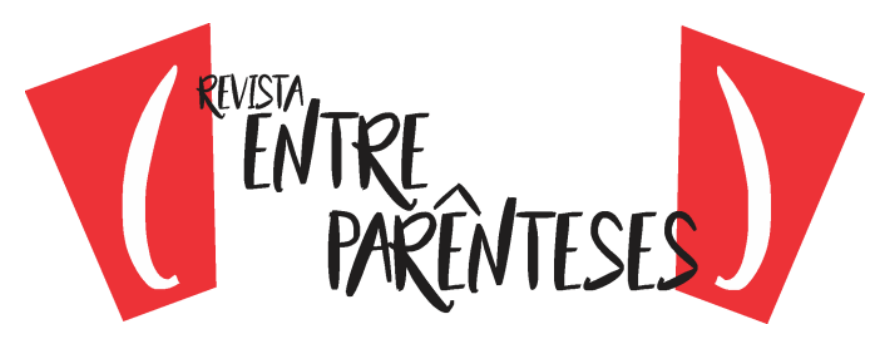

você será visto como alguém que cumpre literalmente as próprias bravatas. (LAUB, 2016, p. 126-127)

É curioso como, apesar disso, respeito e empatia são abordados no livro e o narrador toma consciência de que indivíduos diferentes dele são tratados; o narrador reconhece que pessoas são construções e responsáveis sociais e coletivamente; ele inclusive já fez campanhas em prol de causas sociais. Porém, está explícito que isso não faz dele um ser que não comete erros, mas poderia fazêlo mais humilde. $O$ contrário aparece em um trecho que considero crucial à narrativa e simbólico do pensamento e defesa do narrador sobre suas atitudes, ainda na segunda parte:

Todo fascista julga estar fazendo o bem. Todo linchador age em nome de princípios nobres. Toda vingança pessoal pode ser elevada a causa política, e quem está do outro lado deixa de ser um indivíduo que erra como qualquer indivíduo, em meia dúzia de atos entre os milhares praticados ao longo de quarenta e três anos, para se tornar o sintoma vivo de uma injustiça histórica e coletiva baseada em horrores permanentes e imperdoáveis. (LAUB, 2016, p. 72)

A última parte do livro é representativa como maneira de redenção ao narrador, uma vez que Dani, uma das prejudicadas pelas mensagens divulgadas, cobra de José Victor apenas que ele fale sobre o que ocorreu após a divulgação, sem necessidade de pedidos de desculpa, pois não se sente ofendida pelo exposto, entendendo o contexto das mensagens. É interessante refletir em como, na obra, tem-se o contraponto de uma mulher "histérica", que não aceita a separação e, portanto, divulga conversas privadas que possam causar constrangimento ao ex, e uma mulher, mais jovem e aberta, que aceita a situação, entende o narrador e fica com ele. Há, aqui, mais um reforço de estereótipo de mulheres e personalidades aceitáveis ou não; deve-se ser compreensiva, não inquisitiva.

\section{O julgamento final}




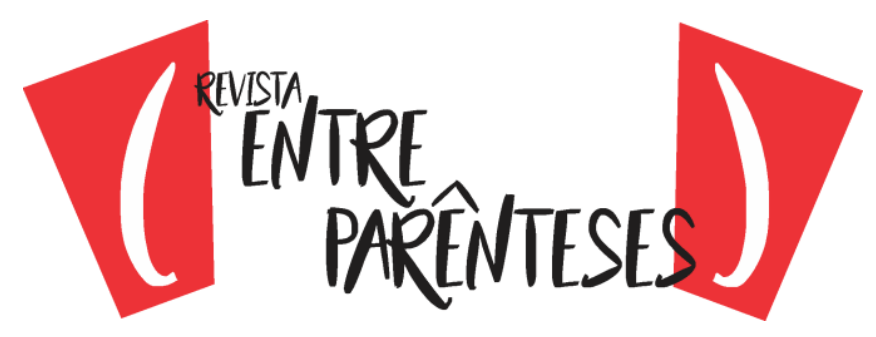

É corriqueiro o crime na internet e, no Brasil, leis garantem punição aos criminosos, apoiada em crimes de injúria e difamação, por exemplo, ou sob lei específica para a internet (Lei $n^{\circ}$ 12.737), tendo em vista que dos dados de uma pesquisa sobre o ano de 2016 apontam que 42,4 milhões de brasileiros foram vítimas de crimes virtuais. Está em pauta como julgar como crime atitudes que violentam, mas não agridem fisicamente, que pode ofender pessoas não envolvidas diretamente no caso, como retrata o livro de Laub.

As/os leitoras sabendo cada aspecto da história por meio da visão de quem cometeu o suposto crime nos leva a crer na humanidade do criminoso; João Victor cometeu erros, ou nem isso, apenas estava conversando e brincando com um amigo. É relevante pensar nas consequências de cada ato, real ou virtual, e esta é uma possibilidade que a leitura da obra nos impõe: pensar sobre nossas atitudes privadas de forma a não ofender o público.

É interessante também refletirmos sobre nosso papel na sociedade concreta e virtual. Somos réus e acusadores o tempo todo em que estamos na internet, pois nos sentimos aptos a julgar qualquer atitude até o momento de julgarem a nossa e sermos nós os passíveis de julgamento. O livro de Laub tem o poder, portanto, de fazer pensar sobre quem somos e o que fazemos nas redes.

\section{Referências}

CRIMES virtuais afetam 42 milhões de brasileiros. Estadão, São Paulo, 2017. Disponível em: <http://economia.estadao.com.br/noticias/releases-ae,crimes-virtuaisafetam-42-milhoes-de-brasileiros,70001644185>. Acesso em: 27 ago. 2017.

DALCASTAGNE, Regina. Personagens e narradores do romance contemporâneo no Brasil: incertezas e ambiguidades do discurso. Diálogos Latinoamericanos, Dinamarca, n. 3, p. 114-130, 2001.

DAL FARRA, MariaLúcia. O narrador ensimesmado: o foco narrativo em Virgílio Ferreira. São Paulo: Ática, 1978.

HAMBURGER, Käte. A lógica da criação literária. São Paulo: Perspectiva, 1975. 


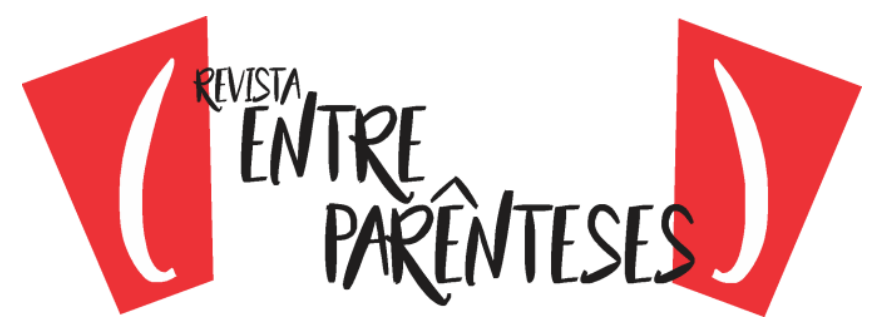

HOLLANDA, Heloísa Buarque. Maldito.com. (s/d). Disponível em: $<$ http://www.heloisabuarquedehollanda.com.br/maldito-com/>. Acesso em 25 ago. 2017.

HOLLANDA, Heloísa Buarque. Quem tem medo da tecnologia? (s/d). Disponível em: <http://www.heloisabuarquedehollanda.com.br/quem-tem-medo-da-tecnologia/>. Acesso em 25 ago. 2017.

HOLLANDA, Heloísa Buarque. Professando as letras: identidades em construção. (s/d). Disponível em: $<$ http://www.heloisabuarquedehollanda.com.br/professando-as-letras-identidadesem-construcao/>. Acesso em 25 ago. 2017.

LAUB, Michel. O tribunal de quinta-feira. São Paulo: Companhia das Letras, 2016.

MICHEL LAUB. Disponível em: <https://michellaub.wordpress.com/biografia-contatoentrevistas/>. Acesso em: 27 jun. 2017.

Recebido em: 11/04/2018

Aceito em: 20/11/2018 